\title{
Papers
}

\section{Effect of the critical care outreach team on patient survival to discharge from hospital and readmission to critical care: non-randomised population based study}

Carol Ball, Margaret Kirkby, Susan Williams

\begin{abstract}
Objectives To determine the effect of the critical care outreach team on patient survival to discharge from hospital after discharge from critical care and readmission to critical care.

Design Non-randomised population based study. Setting Tertiary referral teaching hospital with 1200 beds.

Participants Patients discharged from the critical care unit after their first or only admission for two study periods, 26 February 2000 to 25 February 2001 and 26 February 2001 to 25 February 2002.

Main outcome measures Survival to discharge from hospital after discharge from critical care and readmission to critical care.

Results The introduction of a critical care outreach team improved survival to discharge from hospital after discharge from critical care by $6.8 \%$ (risk ratio 1.08). Readmission to critical care decreased by $6.4 \%$ (0.48).

Conclusions The activity of the critical care outreach team seems to improve patient survival to discharge from hospital and may reduce the number of readmissions to critical care.
\end{abstract}

\section{Introduction}

The report Comprehensive Critical Care identified a strategy for change that has begun to transform the delivery of critical care services in England and Wales. ${ }^{1}$ Many of the recommendations in the report are subsumed under the broad remit of critical care outreach teams. Perhaps the most important of these recommendations was the development of patient at risk teams and follow up services to complement critical care while improving the speed and quality of patient recovery to discharge from hospital. The need for this service was based on several reports, which indicated suboptimal management of both patients discharged from intensive care and patients at risk of deterioration on hospital wards..$^{2-5}$ The same year a report published by the Scottish Executive concluded that outreach teams and follow up would not significantly optimise patient care or affect the workload of intensive care units. ${ }^{6}$
More recently, critical care outreach teams have been challenged to produce robust evidence of effectiveness to justify the substantial investment in them made by the government. ${ }^{7}$ Evidence is emerging from Australia that the activity of medical emergency teams, introduced in the early $1990 \mathrm{~s}$, may substantially reduce the incidence of cardiac arrest and unanticipated admission to intensive care. ${ }^{8}$ Such teams, however, differ from patient at risk teams that have developed in England and Wales. Medical emergency teams are usually a medical team, including a senior nurse, trained and experienced in acute hospital medicine. Patient at risk teams tend to be nurse led..$^{10}$ Therefore the results from Australia cannot be extrapolated to England and Wales, despite both teams responding to early physiological warnings (box). We aimed to determine the effectiveness of follow up services during the period between discharge from critical care to discharge from hospital and on readmission to critical care.

\section{Participants and methods}

The critical care outreach team of the Royal Free Hampstead NHS Trust was established in February 2001. The team of five senior critical care nurses is led by a consultant nurse. The service is available for 12 hours daily. The trust has 1200 beds, including 20 critical care beds. Data collection during the study was

Early warning triggers for patient at risk teams (triggers may be modified)

- Respiratory rate $<8$ breaths $/$ min or $>25$

breaths/min

- Pulse oximetry $<90 \%$ on $>35 \%$ fractional inspired oxygen

- Pulse $<50$ beats/min or $>125$ beats/min

- Systolic blood pressure $<90 \mathrm{~mm} \mathrm{Hg},>200 \mathrm{~mm}$ $\mathrm{Hg}$, or $>40 \mathrm{~mm} \mathrm{Hg}$; less than patient's normal values - Urine output $<30 \mathrm{ml} / \mathrm{h}$ for more than two hours; unless normal for patient

- Sustained alteration in level of consciousness or fall in Glasgow coma scale score of $>2$ in past hour

- Concerns about the patient
Critical Care Unit, Royal Free Hampstead NHS Trust, London NW3 2QG

Carol Ball consultant nurse Margaret Kirkby senior sister critical care outreach team Susan Williams clinical audit manager

Correspondence to: C Ball carol.ball@ royalfree.nhs.uk

bmj.com 2003;327:1014 
Table 1 Most common interventions performed by critical care outreach team

\begin{tabular}{lc} 
Intervention & $\begin{array}{c}\text { No (\%) of } \\
\text { interventions } \\
(\mathbf{n}=2792)\end{array}$ \\
\hline Guiding tracheostomy management & $282(10.1)$ \\
\hline Performing tracheal suction and chest physiotherapy & $243(8.7)$ \\
\hline Guiding management of continuous positive airways pressure & $232(8.3)$ \\
\hline Optimising patient positioning (sitting up, side lying) & $223(7.9)$ \\
\hline Requesting prescription or administration of nebuliser therapy & $199(7.1)$ \\
\hline Requesting repeat blood testing* & $192(6.9)$ \\
\hline Increasing the frequency of CVS/respiratory observations & $155(5.5)$ \\
\hline Starting hourly fluid balance monitoring & $101(3.6)$ \\
\hline Requesting samples be sent for microculture and sensitivity & $89(3.2)$ \\
\hline$*$ Full blood count, urea, and electrolytes.
\end{tabular}

${ }^{\star}$ Full blood count, urea, and electrolytes.

limited to a site with 13 beds owing to the ongoing expansion of the critical care clinical audit team.

\section{Operational policy of team}

Patients discharged from critical care are assessed by the critical care outreach team at least once daily. Any interventions required are performed by the outreach team or by nursing and medical staff on the ward, depending on the skill required. The outreach team alert staff to patients showing deterioration. The emphasis of the follow up service is rehabilitative. Table 1 outlines the most common interventions performed by the outreach team. Table 2 shows the types of referrals to specialists recommended by the outreach team. Patients are discharged from the follow up service once they are making satisfactory progress-no longer require continuous positive airways pressure or a tracheostomy and are not showing warning criteria (see box). Ward staff are encouraged to re-refer patients to the outreach team who are showing any of these criteria. The outreach team uses clinical judgment to assess progress as standardised objective criteria for satisfactory progress have not yet been derived.

\section{Data collection}

We undertook a before and after study using historical controls to determine patient survival to discharge from hospital after discharge from critical care and readmission to critical care. All data were routinely collected as part of the Intensive Care National Audit Research Centre case mix programme. ${ }^{11}$ Data were taken from patient charts, and input was the responsibility of an auditor.

Data were analysed from patients admitted during 26 February 2000 to 25 February 2001 (period 1) and 26 February 2001 to 25 February 2002 (period 2). These represent the periods before and after the introduction of the outreach team. A dataset was prepared

Table 2 Most common referrals to specialists by critical care outreach team

\begin{tabular}{lc} 
Intervention & No (\%) referred $(\mathbf{n}=\mathbf{4 4 2 )}$ \\
\hline Parent medical team & $195(44)$ \\
\hline Speech and language therapists & $53(12)$ \\
\hline Physiotherapist & $49(11)$ \\
\hline Critical care registrar & $48(11)$ \\
\hline Pain management team & $29(7)$ \\
\hline Dietician & $21(5)$ \\
\hline Ear, nose, and throat team & $14(3)$ \\
\hline Various others & $30(7)$ \\
\hline
\end{tabular}

from the patient's first or only admission to critical care during these periods. We excluded patients who died in critical care. Patients were excluded from period 1 if they were admitted during this period but discharged in period 2, as the outreach team could have influenced survival to hospital discharge or readmission. For the same reason patients were excluded if they were firstly admitted and discharged in period 1 , then readmitted and discharged in period 2. To ascertain equivalence between the two groups, risk factors were chosen for their presumed association with mortality based on local audit data-for example, male, aged over 65, acute physiological and chronic health evaluation II (APACHE II) chronic health points, and probability of inhospital mortality-and those associated with readmission-for example, length of stay in critical care and medical or surgical diagnosis. ${ }^{12-14}$

To assess data reliability a $5 \%$ sample of the patients included in the study groups was selected using a computer generated random number sequence. Computerised data were checked against the original records. This was undertaken by staff who had received training in data collection for the Intensive Care National Audit Research Centre case mix programme but had not been involved in the original data entry.

\section{Statistical analysis}

The patient was the sampling unit. The Mann-Whitney $\mathrm{U}$ test and $\chi^{2}$ and $t$ tests were used to evaluate the uniformity of the patient populations for both periods for age, sex, medical or surgical diagnosis, length of stay in critical care, severity of illness in the first 24 hours of admission, and comorbid conditions. Risk ratios and $95 \%$ confidence intervals were calculated for the effect of the outreach team on patient survival to hospital discharge and readmission to critical care. Analyses were performed with intercooled Stata 7.0 for Windows.

A 5\% random sample (24 patients) was taken from the dataset to check the reliability of the data. Overall, $98.7 \%(3529 / 3576)$ of the computerised items for these patients agreed with the original written records (95\% confidence interval $98.3 \%$ to $99.1 \%$ ).

\section{Results}

We found no significant differences between the populations of critical care survivors before and after the introduction of the outreach team for age, sex, medical or surgical diagnosis, length of stay in critical care, severity of illness in the first 24 hours of admission to critical care, or comorbidities (table 3). After the introduction of the outreach team, there was a significant increase in survival to hospital discharge and a significant decrease in number of readmissions to critical care (risk ratios 1.08 and 0.48 , respectively; table 4 ).

\section{Discussion}

Critical care outreach teams seem to improve survival to discharge from hospital after discharge from critical care and may reduce the number of readmissions to a significant extent. The activity of the outreach team differs from that of medical emergency teams and patient at risk teams. Critical care outreach teams have developed on an ad hoc basis in England and Wales. 
They differ widely in composition, ranging from lone consultant nurses to multiprofessional teams, and in their working patterns and activity. ${ }^{10}$ Some outreach teams follow up patients as described in our study, whereas others attend once patients show early warning criteria (see box). The results of our study are therefore not transferable.

Patients are at increased risk of deterioration during the recovery period after discharge from critical care, attributable to early discharge and residual organ dysfunction. ${ }^{12}{ }^{13}$ Both often lead to readmission, which in turn is associated with higher inhospital mortality. ${ }^{13}{ }^{15}$ Although we present only a preliminary examination of what can be achieved through fundamental interventions and referrals made by experienced critical care nurses during the recovery period, our findings do provide some evidence that this type of innovation is worth while for patient survival and readmission.

A recent study could detect no change in patterns of readmission after the introduction of a critical care outreach team. ${ }^{16}$ It is difficult to extrapolate from the report if the operational policy was similar to that described in our study, and although the setting seems similar, a far larger sample was examined. The readmission rate for both study periods was $4.0 \%$, unlike our study, which found a reduction of $12.4 \%$ compared with $6.0 \%$ after the introduction of the outreach team. A readmission rate of $4.0 \%$ is below the national average of $6.3 \%$ reported by the Intensive Care National Audit Research Centre, indicating that there was little room for the effect of the outreach team to be shown in terms of readmission.

Survival to discharge from hospital has been determined in medical patients after discharge from critical care. ${ }^{14}$ These patients were chosen because of the high mortality associated with critical illness. Survival was thought to have been affected by a change in resuscitation status, where seven of the 12 patients who survived critical care had their resuscitation status altered to do not resuscitate. It is unlikely that this applied to our study because survival to discharge improved and it is unlikely that this would have occurred if patients had had their resuscitation status altered. A more unlikely reason is that decisions about not resuscitating were made but that patients then survived to discharge from hospital. Alternatively, the proportion of medical patients differed between the two periods under study, but this was not the case.

\section{Strengths and limitations}

Our study design could have confounded the results; before and after studies are retrospective, therefore variables cannot be controlled. In our study a concomitant innovation in the hospital could have produced the same results. Patients were, however, discharged from critical care to different areas of the hospital, and at the time of the study there was no other innovation that could have had an effect on patients. The median predicted probability of mortality was $16.1 \%$ compared with $20.4 \%$ in the historical cohort. Although this was not statistically significant, part or all of the effect seen might be explained by this difference. Several authors have, however, questioned the ability of the tool to predict mortality and it is currently the subject of further investigation by the Intensive Care
Table 3 Characteristics of critical care survivors for first or only admission to intensive care unit before and after introduction of critical care outreach team

\begin{tabular}{lcc} 
Characteristics & $\begin{array}{c}\text { Before outreach team } \\
(\mathbf{n = 2 0 1 )}\end{array}$ & $\begin{array}{c}\text { After outreach team } \\
(\mathbf{n}=\mathbf{2 6 9})\end{array}$ \\
\hline No $(\%)$ men & $118(59)$ & $160(59)$ \\
\hline Mean $(95 \% \mathrm{Cl})$ age (years) & $51.6(49.1$ to 54.1$)$ & $49.6(47.5$ to 51.8$)$ \\
\hline No $(\%) \geq 65$ years & $49(24)$ & $63(23)$ \\
\hline No $(\%)$ with medical diagnosis & $120(60)$ & $137(51)$ \\
\hline $\begin{array}{l}\text { Median (25th-75th centiles) critical care length of } \\
\text { stay (days) }\end{array}$ & $3.7(1.9-9.0)$ & $4.6(1.7-15.5)$ \\
\hline $\begin{array}{l}\text { No (\%) with APACHE II chronic health points } \\
\text { Mean (95\% Cl) APACHE II score }\end{array}$ & $44(22)$ & $45(17)$ \\
\hline $\begin{array}{l}\text { Median (25th-75th centiles) APACHE II } \\
\text { probability of inhospital mortality }\end{array}$ & $16.4(15.5$ to 17.3) & $16.1(15.3$ to 16.8) \\
\hline
\end{tabular}

APACHE=acute physiological and chronic health evaluation; $\mathrm{P}<0.05$ before and after introduction of outreach team.

Table 4 Risk ratios for effect of introducing critical care outreach team on patient survival to hospital discharge and subsequent readmission to critical care

\begin{tabular}{lccc} 
Patient status & $\begin{array}{c}\text { Before outreach team } \\
(\mathbf{n}=\mathbf{2 0 1})\end{array}$ & $\begin{array}{c}\text { After outreach team } \\
(\mathbf{n = 2 6 9 )}\end{array}$ & Risk ratio (95\% Cl) \\
\hline No $(\%)$ surviving to discharge & $162(81)$ & $235(87)$ & $1.08(1.00$ to 1.18$)$ \\
\hline No $(\%)$ readmitted & $25(12)$ & $16(6)$ & $0.48(0.26$ to 0.87$)$ \\
\hline
\end{tabular}

National Audit Research Centre. The tool therefore might explain some of the variation in outcome but not all of it. ${ }^{17} 18$

Before and after studies may also show a lack of equivalence between comparators, and interventions may vary. Both our groups had similar risk factors. These were chosen for their association with mortality and readmission and seemed to be appropriate for the purposes of our study. The interventions undertaken by team members did vary, possibly owing to length of time available for the intervention or the manner in which the intervention was undertaken by the individual and on a particular day. It is unlikely, however, that one individual or one intervention can be associated with the findings. Rather, the combined effect of the interventions seems to have had a beneficial effect on outcomes.

The use of routine audit data, rather than specific data collected for research purposes, may also have produced erroneous results. The database was examined on a random basis for reliability and seemed sound.

Our small sample size increased the risk of a type 2 error, which is much smaller than those used to test the

\section{What is already known on this topic}

The management of patients on the ward at risk of critical illness is suboptimal

Substantial sums have been invested in the development of critical care outreach teams

Outreach teams were hastily created and their effect on readmission to critical care or survival to hospital discharge was unclear

\section{What this study adds}

Critical care outreach teams seem to improve survival to discharge from hospital and may reduce readmission rates to critical care 
effectiveness of medical emergency teams or the effect on readmission rates. ${ }^{816}$ If the innovation described here had not been introduced so hastily, owing to political imperative, we could have conducted a prospective randomised controlled trial. Evidence for innovation in service delivery will always be prone to limitations where evaluation is not undertaken before wholesale application. Policy makers should consider testing health service innovation using cluster randomised controlled trials with the hospital as the sampling unit. An example of this is the medical early response intervention and therapy study currently being undertaken in Australia to assess medical emergency teams. ${ }^{19}$

Contributors: Heather Byers, Mary Fogarty, Joanna Hoyland, and Richard Ward (members of the critical care outreach team) participated in data collection and analysis. Dominic Cox (clinical scientist) and Demissie Tulu (auditor, Critical Care Audit Team) checked the reliability of the dataset. Steve Shaw (lead consultant for critical care) and Julian Howard (consultant critical care) critically reviewed drafts of the manuscript. John Emberson (statistician, British regional heart study) provided advice on the analysis and interpretation of data. SW compiled and analysed the database. $\mathrm{CB}$ and MK contributed to the concept, design, and implementation of the study, drafted the manuscript, and read and approved the final version. All authors will act as guarantors for the paper.

Funding: None.

Competing interests: None declared.

Ethical approval: Permission from the local ethics committee was not sought as the study involved secondary analysis of audit data collected on a routine basis.
1 Department of Health. Comprehensive critical care. London: DoH, 2001.

2 McQuillan P, Pilkington S, Allan A, Taylor B, Short A, Morgan G, et al Confidential enquiry into quality of care before admission to intensive care. BMJ 1998;316:1853-8.

3 McGloin H, Adam SK, Singer M. Unexpected deaths and referrals to intensive care of patients on general wards. Are some cases potentially avoidable? J R Coll Physicians London 1999;33:255-8.

4 Goldhill DR, Worthington L, Mulcahy A, Tarling M, Sumner A. The patient at risk team: identifying and managing seriously ill ward patients. Anaesthesia 1999;54:853-60.

5 Garrard C, Young JD. Sub-optimal care of patients before admission to intensive care. BMJ 1998;316:1841-2

6 Scottish Executive, Health Department. Better critical care-report of a short-life working group on ICU and HDU issues. Edinburgh: Scottish Executive, 2000.

7 Cuthbertson BH. Outreach critical care-cash for no questions? $\mathrm{Br} J$ Anaesth 2003;90:4-6.

8 Buist MD, Moore GE, Bernard SA, Waxman BP, Anderson JN, Nguyen TV. Effects of a medical emergency team on reduction of incidence of and mortality from unexpected cardiac arrests in hospital: preliminary study. BMJ 2002;324:387-90.

9 Bristow PJ, Hillman KM, Chey T, Daffurn K, Jacques TC, Norman SL, et al. Rates of in-hospital arrests, deaths and critical care admissions: the effect of the medical emergency team. Med J Aust 2000;173:236-40.

10 Goldhill DR, McNarry A. Intensive care outreach services. Curr Anaesth Crit Care 2002,13:356-61.

11 Intensive Care National Audit Research Centre case mix programme datase specification. Full release version 2.0. London: ICNARC, 2 Jul 1997.

12 Daly K, Beale R, Chang RWS. Reduction in mortality after inappropriate early discharge from critical care unit: logistic regression triage model. BMJ 2001;322:1-5.

13 Metnitz PG, Fieux F, Jordan B, Lang T, Moreno R, Le Gall JR. Critically ill patients readmitted to intensive care units-lessons to learn. Intensive Care Med 2003;29:241-8.

14 Trivedi M, Ridley S. Intermediate outcome of medical patients after intensive care. Anaesthesia 2001;56:841-6.

15 Rosenberg AL, Watts C. Patients readmitted to ICUs: a systematic review of risk factors and outcomes. Chest 2000;118:492-502.

16 Leary T, Ridley S. Impact of an outreach team on re-admissions to a critical care unit. Anaesthesia 2003;58:328-32.

17 Goldhill DR, Withington PS. The effect of casemix adjustment on Goldhill DR, Withington PS. The effect of casemix adjustment
mortality as predicted by APACHE 2. Crit Care Med 1996;22:415-9.

18 Patel PA, Grant BJB. Application of mortality prediction systems to individual critical care units. Crit Care Med 1999;25:977-82.

19 Hillman K. Outreach critical care. [Letter.] Br J Anaesth 2003;90:808. (Accepted 15 September 2003) 